\title{
Stage IVA Lip and Oral Cavity Cancer AJCC v8
}

National Cancer Institute

\section{Source}

National Cancer Institute. Stage IVA Lip and Oral Cavity Cancer A/CC v8. NCI Thesaurus. Code C132733.

Stage IVA includes: (T4a, N0, M0); (T4a, N1, M0); (T1, N2, M0); (T2, N2, M0); (T3, N2, M0); (T4a, N2, M0). T4a (lip): Tumor invades through cortical bone or involves the inferior alveolar nerve, floor of mouth, or skin of face (i.e., chin or nose). T4a (oral cavity): Tumor invades adjacent structures only (e.g., through cortical bone of the mandible or maxilla, or involves the maxillary sinus or skin of face). Note: Superficial erosion of bone/tooth socket (alone) by a gingival primary is not sufficient to classify a tumor as T4. T1: Tumor size $2 \mathrm{~cm}$ or less in greatest dimension and $5 \mathrm{~mm}$ or less DOI. T2: T umor size $2 \mathrm{~cm}$ or less in greatest dimension, DOI greater than $5 \mathrm{~mm}$ and equal or less than $10 \mathrm{~mm}$ or tumor greater than $2 \mathrm{~cm}$ but $4 \mathrm{~cm}$ or less in greatest dimension and $10 \mathrm{~mm}$ or less DOI. T3: Tumor size greater than $4 \mathrm{~cm}$ or any tumor greater than $10 \mathrm{~mm}$ DOI. N0: No regional lymph node metastasis. N1: Metastasis in a single ipsilateral lymph node, $3 \mathrm{~cm}$ or smaller in greatest dimension and ENE(-). N2: Metastasis in a single ipsilateral lymph node, $3 \mathrm{~cm}$ or smaller in greatest dimension and $\mathrm{ENE}(+)$; or larger than $3 \mathrm{~cm}$ but not larger than $6 \mathrm{~cm}$ in greatest dimension and ENE (-); or metastases in multiple ipsilateral lymph nodes, none larger than $6 \mathrm{~cm}$ in greatest dimension and ENE(-); or metastases in bilateral or contralateral lymph nodes, none larger than $6 \mathrm{~cm}$ in greatest dimension, ENE(-). M0: No distant metastasis. (AJCC 8th Ed.) 